\title{
Quality of Life in Heroin Users Attending Substitution Treatment: A Multicenter Study in Italy
}

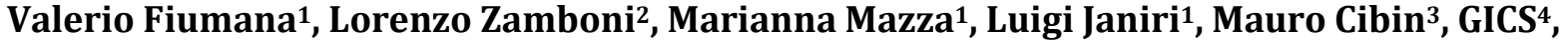 Fabio Lugoboni2}

${ }^{1}$ Institute of Psychiatry and Clinical Psychology, Catholic University of Sacred Hearth, Rome, Italy

${ }^{2}$ Addiction Unit, Department of Medicine, Verona University Hospital, Verona, Italy

${ }^{3}$ Psychiatry and Addictive Behaviours Department, Local Health Authority, Mirano Venice, Italy

${ }^{4}$ Group for Scientific Cooperation between Public Health Authority Centres for Drug Users, Verona, Italy

Email: v.fiumana@libero.it, lorenzo88z@yahoo.it, mariannamazza@hotmail.com, luigi_janiri@fastwebnet.it, m.cibin@libero.it,

fabio.lugoboni@ospedaleuniverona.it

How to cite this paper: Fiumana, V., Zamboni, L., Mazza, M., Janiri, L., Cibin, M., GICS and Lugoboni, F. (2016) Quality of Life in Heroin Users Attending Substitution Treatment: A Multicenter Study in Italy. Health, 8, 1195-1208.

http://dx.doi.org/10.4236/health.2016.812123

Received: June 23, 2016

Accepted: September 4, 2016

Published: September 7, 2016

Copyright $\odot 2016$ by authors and Scientific Research Publishing Inc. This work is licensed under the Creative Commons Attribution International License (CC BY 4.0).

http://creativecommons.org/licenses/by/4.0/ (c) (i) Open Access

\begin{abstract}
Quality of life (QoL) is an important measure to verify the effectiveness of therapy in substance use disorders (SUD). In this cross-sectional, multicenter study QoL has been measured in 1057 heroin dependents attending SerDs ("Servizi per le Dipendenze", Italian National Health System Services for Addictions) and has been correlated with demographic variables and drug treatment. QoL has been measured by using GHQ-12 (12-item General Health Questionnaire), a self-administered questionnaire whose value is inversely correlated with the QoL. The median value of GHQ-12 in the study population was 12 (interquartile range [IQ] 9 - 18): 640 patients $(60.6 \%)$ scored $<15$ which relates with a sufficiently good QoL, 257 (24.3\%) scored between 15 - 20, and 160 (15.1\%) scored >20 points at the GHQ-12, which relates with a bad QoL. Female population showed higher GHQ12 scores when compared to male population (14 [IQ 9 - 19] vs. 12 [IQ 9 - 17], p = 0.03). Similarly, unemployed patients showed higher GHQ12 scores when compared to employed patients (15 [IQ 10 - 20] vs. 12 [IQ 8 - 16], p < 0.00). Unemployment (OR 2.09, CI 95\% $1.5-3.0, \mathrm{p}<0.00$ ), non-opioid psychopharmacological treatment (OR 1.82, CI 95\% $1.3-2.6, \mathrm{p}=0.00$ ) and substitution therapy with buprenorphine (OR 0.55, CI 95\% $0.3-0.8, \mathrm{p}=0.01$ ) were independent predictors of GHQ-12 $>20$. Results show that most of patients receiving care for heroin dependence at SerDs have a positive assessment of their quality of life, and that being unemployed and having a dual diagnosis are predictors of poor QoL. Besides, data suggest that assuming buprenorphine could be a protective factor for QoL.
\end{abstract}




\section{Keywords}

Quality of Life, Heroin Addiction, GHQ-12, Substitution Therapy, Dual Diagnosis

\section{Introduction}

The ultimate aim of medicine has always been to cure patients. In chronic illnesses, however, complete cure is seldom achievable, and therefore physicians try to maximize life expectancy or at least optimize quality of life (QoL). Monitoring QoL can be an helpful way to measure the effectiveness of therapy [1]. Measuring QoL is considered essential for the evaluation of quality of provided care, rather than the classic methods of complete recovery (and compliance). These new ways of monitoring are necessary in times of limited resources. Substance use disorders (SUD) often adopt the characteristics of chronic illnesses, especially in comorbidity with other mental disorders, by having a fluctuating course of remission and relapse, accompanied by deterioration in labour, social and relational, skills as identified by the DSM V diagnostic criteria [2]. With these patients it is necessary, parallel to conventional therapy, to implement other ways of preserving QoL, for example rehabilitating interventions [3].

QoL is a complex concept, defined by the WHO [4] as "individual's perception of their position in life, in context of the culture and value systems in which they live and in relation to their goals, expectations, standards and concerns". It is affected by several factors: physical health, psychological state, level of autonomy, social relationships, personal beliefs and relationship with the environment. It has been shown that, above a certain standard of living, QoL is mainly linked to subjective experiences such as self-realization, self-esteem, pleasure, inner harmony, love and freedom [5].

Studies on QoL in addiction disorders are scarce. In particular studies on QoL in heroin dependent people (HDP) have mainly taken into account the stabilizing and normalizing role of substitution therapy, in most cases by methadone, but also buprenorphine. Important factors have been investigated, such as risk of overdose, the impact of HIV and hepatitis, risk of imprisonment, the co-use of other drugs and treatment compliance [6]-[14]. In these studies opiate dependents showed low QoL compared with the general population and patients with various medical illnesses and, generally, participation in substitution treatment had positive effect on individual QoL [15]. Some socio-demographic variables appear to correlate positively with QoL. Legal job, for example, is one of the most successful ways to increase self esteem [16]. Clearly, employment turned out to be an important element in experiencing a good QoL, by reducing economical difficulties and expanding the sense of personal fulfillment and social integration. Also one's own marital satisfaction is a sizeable and significant correlate of life satisfaction, momentary happiness, health and well-being [17] [18]. In studies regarding QoL in relation to residence (urban or rural, urban or suburban), small towns seem to favor a better quality of life [19] [20].

Studies on QoL have often focused on the elderly population suffering from other 
chronic diseases. Literature about SUD and QoL offers conflicting opinions [21]-[27]. In this study QoL has been measured in heroin dependents attending SerDs ("Servizi per le Dipendenze", Italian National Health System Services for Addictions) and has been correlated with demographic variables and drug treatment, in order to identify subgroups that most benefit from different interventions and to improve clinical practices. Primary aim of the study was to investigate QoL in patients attending SerDs for heroin dependence and correlate results with demographic variables and drug treatment (substitution therapy and non opioid psychiatric drugs). Secondary aim of the study was to observe any difference in the QoL in patients attending Urban or Suburban SerDs.

\section{SerDs}

SerDs (Servizi per le Dipendenze, National Italian Health System Services for Addictions) are the Italian National Health System Services dedicated to care, prevention and rehabilitation of both substance and behavioral addictions. Individuals with occasional and sporadic abuse are normally better served in primary care and are not included in the SerDs. SerDs are spread throughout the country and have an homogeneous organization and intervention models. Access and all offered services are free. Each SerD provides personalized treatments based on individual characteristics and on the type of dependence. Treatments include: opioid substitution therapy (such as buprenorphine or methadone), health care for diseases related to drug use (e.g. HIV and viral hepatitis), mental health care for dual diagnosis, non-opioid psychopharmacological treatment. SerDs also provide the main psychosocial treatments and other rehabilitative interventions; they provide visibility for vacancies and collaborate with Therapeutic Communities and 12-Steps groups (Alcoholics Anonymous, Narcotics Anonymous, Gamblers Anonymous). In these centers no specific criteria or regulations were established concerning the duration of the various therapies. To use substitution therapy is necessary for the patient to test positive for heroin at a drug test and to present with a history of heroin addiction.

\section{Materials and Methods}

\subsection{Study Design}

In this cross-sectional, multicenter study data were drawn from a cohort of 1057 patients attending 21 SerDs in the North of Italy. Data were collected from July to September 2014. All subjects had a history of varying severity of heroin dependence, used in different ways depending on the case (injected or smoked). No other specific inclusion or exclusion criterion was considered. A trained nurse delivered the questionnaires and data sheets to participating patients, in order to optimize patients' privacy and spontaneity, as nurses are less involved in therapy compared to doctors and psychologists. All patients provided written informed consent before beginning any study activities. The protocol was approved by the local Ethical Review Board. The average participation rate in the study was $68 \%$ and $9 \%$ of completed questionnaires 
were excluded from the sudy because illegible or incomplete.

\subsection{GHQ-12}

The GHQ-12 (General Health Questionnaire 12-item) was used to assess overall health. GHQ-12 is a questionnaire developed during the 70s [28] [29] to identify two main problem categories: inability to function normally and the presence of new stress factors. The GHQ-12 is a widely used screening test to measure QoL from a psychosocial point of view. The validated Italian version [30] [31] of the questionnaire was used in the present study. The GHQ-12 determines, through 12 questions, whether the subject has recently (i.e. in the last four weeks) experienced particular symptoms or behaviours. Each item is scored on a four-point Likert scale ("less than usual" (0 points), "no more than usual" ( 1 point), "a little more than usual" ( 2 points), and "much more than usual" (3 points)). The sum of all values leads to a total score, which goes from 0 to 36 points. Patients scoring $<15$ show no discomfort. Patients with scores $\geq 15$ were considered "cases on the GHQ-12", i.e. with a probability of more than $80 \%$ of experiencing psychosocial malaise [28]. Patients exceeding 20 points on the questionnaire were classified as suffering from a severe psychosocial disorder.

\subsection{Statistical Analyses}

Continuous variables with skewed distribution are reported as median (1st-3rd quartile), while discrete variables are reported as count and percentages. Mann-Whitney U, $\chi^{2}$, and Fisher exact tests were applied for bivariate analyses when appropriate. All collected variables were tested for bivariate association with GHQ-12 according to the pre-specified cut-offs, and nominally significant covariates $(\mathrm{p}<0.05)$ were simultaneously included into a multivariable logistic regression model to identify independent predictors and to calculate their adjusted odd ratios (ORs) with associated $95 \%$ confidence intervals (CI). The Hosmer and Lemeshow goodness-of-fit test was used to assess model calibration. The final regression model included the following variables: age, sex, marital status, employment, SerDs of enrolment, level of education and pharmacological treatment. All tests were two-sided and an alpha level of 0.05 was considered statistically significant.

\section{Results and Discussion}

\subsection{Demographics}

A total of 1057 patients from 21 SerDs were included in the study. Of these 651 (61.6\%) were recruited in urban SerDs and 406 (38.4\%) in suburban SerDs. Main characteristics of the patients are summarized in Table 1. Median patient age was 38 years (IQ 30 46), with 797 (75.4\%) males; 66.5\% patients were single, 15.8\% married, 15.1\% separated/divorced, and $2.6 \%$ widowed. Level of education was primary school degree in 618 (58.5\%), secondary school degree in 411 (38.9\%) and bachelor's degree in 28 patients (2.6\%). Patients with a regular and legal job were 654 (61.9\%), while the remaining were retired, unemployed or students. $413(39.1 \%)$ patients were prescibed non opioid 
Table 1. Demographic characteristics.

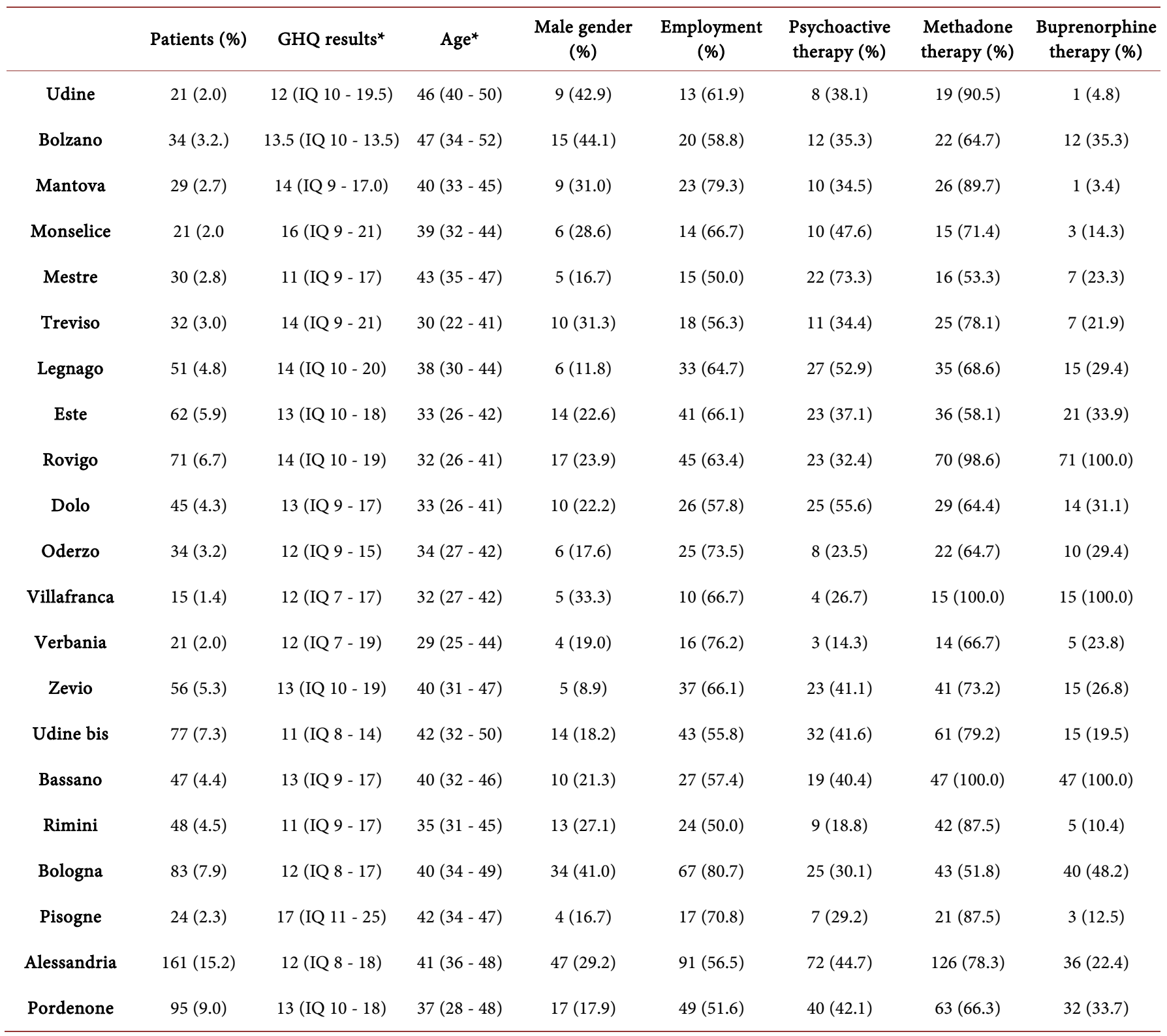

*Expressed as Median (interquartile range).

psychiatric drug treatment for a dual diagnosis. Among these: 49 were taking antidepressants, 252 anxiolytics/hypnotics and 70 more than one drug. 1030 patients were receiving substitution therapy with methadone or buprenorphine for at least 3 months, 788 (74.6\%) received substitution therapy with methadone, and 242 (22.9\%) with buprenorphine. The $90 \%$ of the study group was smoking tobacco.

\subsection{Quality of Life}

The median value of GHQ-12 in the study population was 12 (interquartile range [IQ] 9 - 18): 640 patients $(60.6 \%)$ scored <15, $257(24.3 \%)$ scored between $15-20$, and 160 
(15.1\%) scored $>20$ points. The comparison of GHQ-12 excluded significant differences between centers $(\mathrm{p}=0.13)$ but revealed an inhomogeneous distribution of patients with highest GHQ-12 score (ranging from $3.6 \%$ to $28.1 \%$ of individual SeRDs population, $\mathrm{p}$ $=0.02$ ), while percentages of patients with a score $<15$ (from $41.7 \%$ to $76.6 \%, p=0.20$ ) and between 15 - 20 (from $6.7 \%$ to $34.0 \%, \mathrm{p}=0.41$ ) were comparable.

Comparison between urban and suburban centers (i.e. patient volume) showed no significant difference in GHQ-12 results with a similar median test value (12 [IQ 9 - 17] vs. 13 [IQ 9 - 19], $\mathrm{p}=0.20$, respectively). Consistently, the analysis of patient categories according to the pre-specified cut-off values, revealed a comparable proportion of patients with $<15(61.1 \%$ vs. $59.6 \%, p=0.62),>15<20(25.0 \%$ vs. $23.2 \%, p=0.48)$ and $>20$ score $(17.2 \%$ vs. $13.8 \%, \mathrm{p}=0.13)$ in urban centers vs. suburban centers (Figure 1). Overall, female population showed higher GHQ-12 scores when compared to males (14 [IQ 9 - 19] vs. 12 [IQ 9 - 17], $\mathrm{p}=0.03$ ) with no difference between urban and suburban SerDs (Figure 2). Similarly, unemployed patients showed higher GHQ-12 scores when compared to those employed (15 [IQ $10-20$ ] vs. 12 [IQ $8-16$ ], $\mathrm{p}<0.00$ ). The presence of opioid substitution treatment (15 [IQ $11-20$ ] vs. 12 [IQ $8-17$ ], p $<0.00$ ) and substitution therapy with methadone (13 [IQ 9 - 18] vs. 12 [IQ $8-17$ ], p < 0.00) were associated with a significant higher GHQ-12 scores; conversely, patients on treatment with buprenorphine (12 [IQ 8 - 16] vs. 13 [IQ 9 - 18], p = 0.00) showed lower GHQ-12 median values (Figure 3).

\subsection{Predictors of Quality of Life}

Table 2 shows the main predictors of GH-Q12 at the adjusted multivariable regression analysis. After adjustment for potential confounding factors, the unemployment (OR 1.91, CI 95\% $1.5-2.5, \mathrm{p}<0.00$ ), separated/divorced status (OR 1.53, CI 95\% $1.1-2.2, \mathrm{p}$ $=0.02)$, psychopharmacological treatment (OR 1.99, CI 95\% $1.5-2.6, \mathrm{p}<0.00)$, and substitution therapy with buprenorphine (OR 0.73 , CI 95\% $0.5-1.0, \mathrm{p}=0.05$ ) were independent predictors of GHQ12 $>15$. When a value $>20$ was considered as cut-off, the

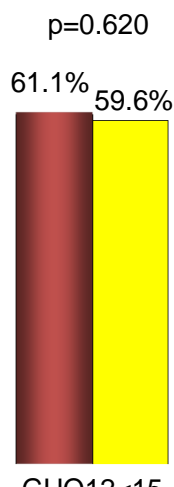

GHQ12<15

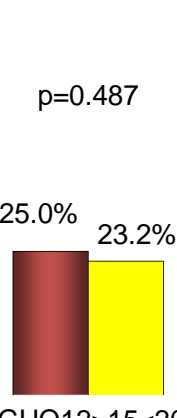

GHQ12 $>15<20$
Qurban centers $\square$ suburban centers

Comparison among urban vs. non urban centers

Figure 1. Distribution of GHQ12 (General Health Questionnaire 12 -item) scores in urban and suburban centers. 


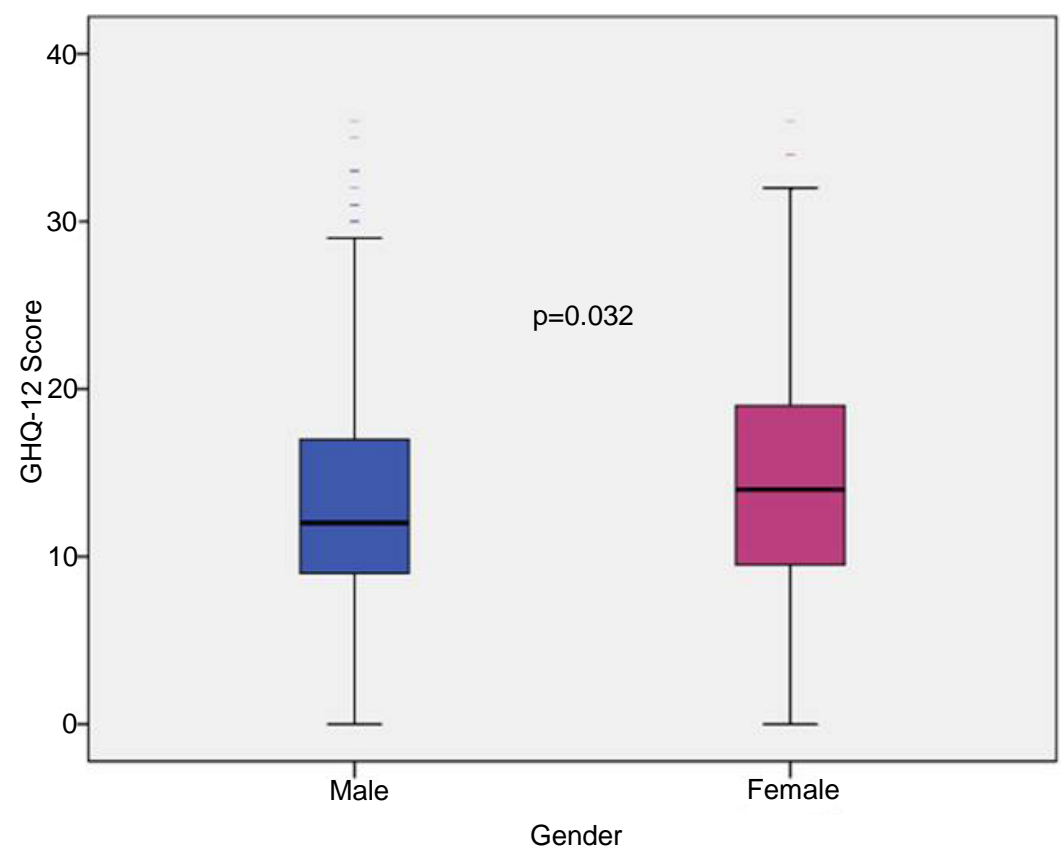

Figure 2. Comparison of GHQ12 (General Health Questionnaire 12-item) score between male and female. The thick black line represent median.

only independent predictors of GHQ12 score were unemployment (OR 2.09, CI 95\% $1.5-3.0, \mathrm{p}<0.00$ ), psychopharmacological treatment (OR 1.82, CI 95\% $1.3-2.6, \mathrm{p}=$ 0.00 ) and substitution therapy with buprenorphine (OR 0.55, CI 95\% $0.3-0.8, \mathrm{p}=$ $0.01)$.

The sex distribution was in line with literature [32] [33]. The average age of our sample (38.68 years) confirmed that the Italian rehabilitation center population is aging [34].

The GHQ-12 is preferable over a test like the SF-36 (Short Form 36 Items Health Survey), because the latter is more orientated towards organic conditions [1]. The male subjects showed to have an overall better QoL. In general, females were subjected to a more severe addiction [35] [36], but not for specific opioid dependence [36]. The percentage of tobacco smokers ( $90 \%$ of the sample) is in line with about $82 \%$ found in prevoius studies [37].

In our population, being married seems to have a beneficial effect on QoL. Indeed, being separated or divorced was an independent predictor of GHQ-12 $>15$. We have no data about the extent of marital satisfaction in married patients neither about the level of emotional and sexual satisfaction of single or divorced subjects [17] [18] but our clinical experience shows that many addicts divorced are recognized as guilty of the separation from the spouse, and therefore must pay alimony. This can impact on the economic autonomy of the patient and severely affect their QoL.

Our study showed that subjects not using any psychopharmacological treatment, and therefore probably not displaying any comorbid mental disorders, had a significantly better QoL than subjects who did. Indeed, psychiatric drug treatment is an independent 


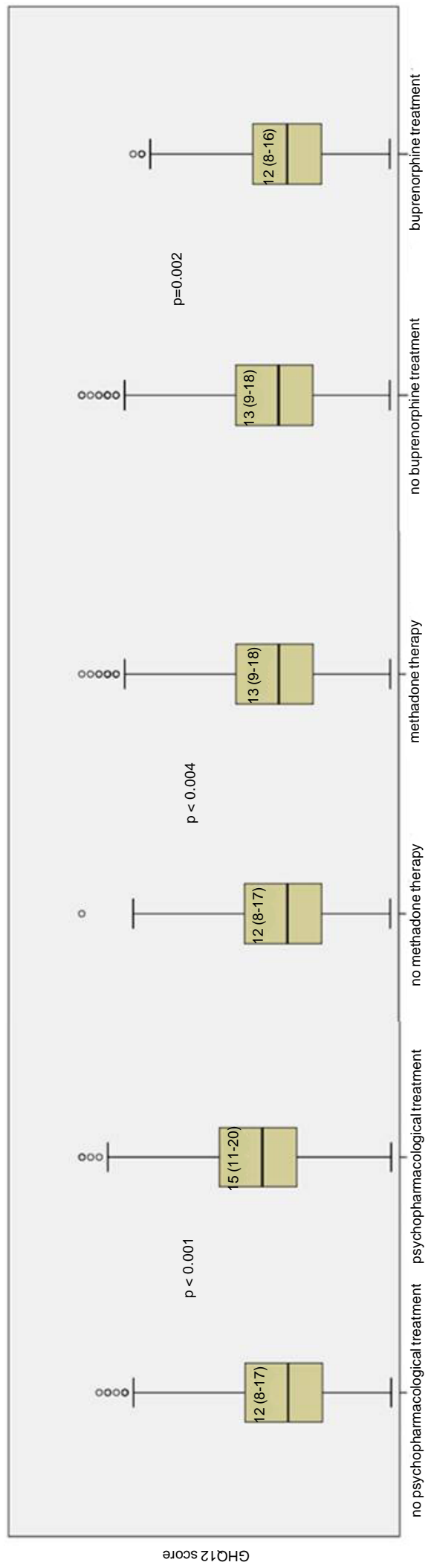

Figure 3. Comparison of GHQ12 (General Health Questionnaire 12-item) scores according to pharmacological treatment. 
Table 2. Predictive value of demographic and clinical characteristics in GHQ12 (General Health Questionnaire 12-item) score.

\begin{tabular}{lll}
\hline GHQ12 $>15$ & & \\
\hline Unemployment & OR 1.91, CI 95\% 1.5 - 2.5 & $<0.001$ \\
Separated/divorced status & OR 1.53, CI 95\% $1.1-2.2$ & 0.018 \\
Psychoactive treatment & OR 1.99, CI 95\% $1.5-2.6$ & $<0.001$ \\
Buprenorphine treatment & OR 0.73, CI 95\% 0.5 - 1.0 & \\
\hline GHQ12 >20 & & $<0.05$ \\
\hline Unemployment & OR 2.09, CI 95\% $1.5-3.0$ & 0.001 \\
Separated/divorced status & OR 0.90, CI 95\% $0.3-2.8$ & 0.001 \\
Psychoactive treatment & OR 1.82, CI 95\% $1.3-2.6$ & 0.013 \\
\hline Buprenorphine treatment & OR 0.55, CI 95\% $0.3-0.8$ & \\
\hline
\end{tabular}

predictor of GHQ-12 >15 and of GHQ-12 >20. As concerning dual diagnosis, it is important to keep in mind that addiction and psychiatric disorders influence each other and so they do not just often exist simultaneously, but rather overlap, resulting in new and even more complex mental, relational and existential difficulties [38].

In this study, subjects with substitution therapy (methadone and buprenorphine) showed a QoL below the threshold of suffering. This important result further justifies the replacement therapy rational. Our study also seems to suggest that buprenorphine treatment can lead to the development of a better QoL compared to methadone, as previously reported in literature [15]. Treatment with buprenorphine seem to represent a protective independent predictor of GHQ-12 >15 and of GHQ-12 $>20$. This could be due to the fact that the buprenorphine is probably better restricted to those patients with mild-moderate dependence [39] and then, perhaps, with a better QoL, whereas methadone can be used with all levels of dependence but especially in the more severe forms.

An interesting result is the effect of having an occupation. The fact that the majority of the population in our sample had a job is in contrast with DSMV criteria n5 [2], but it is in line with other studies from the North-East of Italy, where a significant relation was found between employment and relational skills in heroin dependent patients frequenting SerDs [33] [34] [40]. In our study being unemployed proved to be the most statistically significant predictor for a poor QoL. This may depend on the decrease of self-esteem but also on the lack of economic independence in order to have their own home, eat what they like and be part of the consumer society. Data on these specific items were not collected in our study. However, our clinical experience shows us how those elements are often experienced by patients as elements of suffering. There were no significant differences among people living in province capitals (recruited in urban SerDs) and people from smaller towns (suburban SerDs). This could be due to similar 
living standards in the cities where the survey was taken, which are basically all in the same geographical region (North-East Italy).

The finding that an important part (60.5\%) of our sample scored a QoL below the threshold of psychological and physical suffering, by other means experiencing an acceptable QoL, is quite surprising as these people are considered extremely afflicted by their condition. Hypotheses to explain these results are numerous, but common roots might be in attending SerDs. These SerDs facilities offer various treatment possibilities. Substitution therapy, according to its therapeutic rationale, has a stabilizing effect heroin dependence, reducing the risk of relapse and hence aid the patient to accomplish a stable planning in labor, relational and social areas. The SerD also offers psycho-therapy, in groups as well as individual, rehabilitation programs, and self-help groups based on the model of the Alcoholics Anonymous. At the light of the above, the visibiliy for vacancies plays a very important role. These interventions do not only increase patients understanding of their disease and the ability to cope with addiction- derived impulses, but also provide a social environment in a specific setting: taking care of themselves. Further on, the SerDs staffs can act as a mediator in handling other problems, for example by collaborating with other specialists to treat organic or psychiatric conditions.

This study has its strengths but also certain limitations. The number and the high rate of participants and also the multicenter design are strong points. Quality of life is rarely assessed in opioid substitution treatment because of a bias in the treatment literature towards measuring abstinence outcomes only, which is an inappropriate and unrealistic approach to measuring quality of care for what is now recognized as a chronic and frequently relapsing disease. This study also benefits from being conducted in the real-world context of 21 public opioid use treatment programs providing services in North East Italy. A limitation is the incompleteness of data about cases of dual diagnosis, amount of replacement therapy prescribed to patients, and severity of addiction. These items may therefore be subjected to further and future studies to explore the Qol in HDP and in cases of dual diagnosis. Moreover, the locality where the study took place is generally associated, at least in Italy, with high life standards and with a good welfare. It would be interesting to conduct this same survey in other parts of Italy where living standards are generally lower, for example in the middle and south of the Country. Finally, tough the $68 \%$ response rate can be considered considerable, it cannot be excluded that individuals with better quality of life could be over represented among the respondents.

\section{Conclusion}

The measure of QoL is considered essential in the evaluation of the quality of provided care, rather than the classic methods of compliance and complete recovery. These new ways of monitoring are necessary in times of limited resources. Some socio-demographic variables are independent predictors for a poor QoL for different reasons. Being unemployed can lower self-esteem and create economic problems. Having a psychiatric disorder concomitant to heroin dependence can worsen the complexity of the clinical 
picture and increase the suffering of the patient. In our population, both methadone and buprenorphine were associated with a QoL below the threshold of sofference, and buprenorphine performed slightly better. Moreover, the use of buprenorphine appeared to be a protective factor against the development of a worse QoL. The greater percentage $(60.5 \%)$ of our subjects scored a QoL below the threshold of psychological and physical suffering, by other means was experiencing an acceptable QoL. Hypotheses to explain these results are numerous, but common roots might be found in the fact that in Italy addicted patients have the possibility to attend the SerDs. SerDs centers are able to provide a complete and continuous care in comparison to other healthcare services, promoting patients' health and QoL and guiding treatment providers towards targeted and personalized therapies.

\section{Acknowledgements}

Our thanks go to all SerDs that participated in the study (Udine, Bolzano, Mantova, Monselice, Mestre, Treviso, Legnago, Este, Rovigo, Dolo, Oderzo, Villafranca, Verbania, Zevio, Udine, Bassano, Rimini, Bologna, Pisogne (BS), Alessandria, Pordenone).

We would also acknowledge Coco Walstra, student researcher at VUmc Amsterdam, Holland, for her help in English translation of the paper.

Members of GICS active in collecting data include: Arzillo C, Benigna L, Bersani N, Bersani P, Betti O, Biasin C, Bossi C, Bottazzo A, Bove A, Caccamo E, Cancian S, Cantanchin F, Cantiero D, Canzian G, Cargnelutti D, Casalboni D, Casari R, Casarini R, Cibin M, Civitelli P, Cozzi T, De Cecco L, Del Zotto R, Dellantonio E, Dersini F, Duranti I, Faccini M, Fadelli M, Favero E, Fona B, Fontana N, Franceschini A, Gaiga E, Gardiolo M, Gentile N, Gervino D, Ghezzo N, Giacomin MA, Kashanpour H, Lietta P, Manera E, Manzato E, Mazzo M, Meneghello D, Mihalcea C, Milan E, Montresor M, Moratti E, Morbioli L, Musso D, Musso M, Pani A, Pavani V, Peroni F, Pellachin P, Piazza M, Pieri MC, Prosa D, Pupulin B, Rescigno B, Resentera C, Ricci C, Righetti P, Ripoli MA, Riscica P, Rizza C, Rizzetto V, Rossi A, Rovea A, Ruffato A, Ruzziconi C, Sabbion R, Santo E, Scarzella M, Sembianti N, Simonetto P, Smacchia C, Stellato M, Stimolo C, Suardi L, Vaiana A, Zavan V, Zerbetto E, Zerman M.

\section{Conflict of Interests}

The authors declare no conflict of interests.

\section{References}

[1] Conti, L. (2002) Repertorio delle scale di valutazione in psichiatria. S.E.E. Società Editrice Europea, Firenze.

[2] DSM, V. (2014) Diagnostic and Statistical Manual of Mental Disorder. 5th Edition, Raffello Cortina Editore, Milano.

[3] Davidson, L. and White, W.J. (2007) Recovery Oriented Rehabilitation-The Concept of Recovery as an Organizing Principle for Integrating Mental Health and Addiction Service. The Journal of Behavioral Health Services and Research, 34, 109-120. http://dx.doi.org/10.1007/s11414-007-9053-7 
[4] World Health Organization (1997) WHOQOL, Measuring Quality of Life Division of Mental Health and Prevention of Substance Abuse.

[5] Skantze, K., Malm, U., et al. (1992) Comparison of Quality of Life with Standard of Living in Schizophrenic Outpatients. The British Journal of Psychiatry, 74, 1217.

[6] Vorma, H., Naukkarinen, H., Sarna, S. and Kuoppasalmi, K. (2004) Symptom Severity and Quality of Life after Benzodiazepine Withdrawal Treatment in Participants with Complicated Dependence. Addictive Behaviors, 29, 1059-1065.

http://dx.doi.org/10.1016/j.addbeh.2004.03.003

[7] Brugal, M.T., Domingo-Salvany, A., Puig, R., Barrio, G., Garcia, D.O. and de la Fuente, L. (2005) Evaluating the Impact of Methadone Maintenance Programmes on Mortality due to Overdose and Aids in a Cohort of Heroin Users in Spain. Addiction, 100, 981-989. http://dx.doi.org/10.1111/j.1360-0443.2005.01089.x

[8] Torrens, M., San, L., Martinez, A., Castillo, C., Domingo-Salvany, A. and Alonso, J. (1997) Use of the Nottingham Health Profile for Measuring Health Status of Patients in Methadone Maintenance Treatment. Addiction, 92, 707-716.

http://dx.doi.org/10.1111/j.1360-0443.1997.tb02937.x

[9] Brunette, M.F., Douglas, L., Haiyi, X. and Robert, E.D. (2003) Benzodiazepine Use and Abuse among Patient with Severe Mental Illness and Co-Occurring Substance Use Disorder. Psychiatry Services, 54, 1395-1399. http://dx.doi.org/10.1176/appi.ps.54.10.1395

[10] Ahern, J., Stuber, J. and Galea, S. (2007) Stigma, Discrimination and the Health of Illicit Drug Users. Drug Alcohol Dependence, 11, 188-196. http://dx.doi.org/10.1016/j.drugalcdep.2006.10.014

[11] Peles, E., Schreiber, S. and Adelson, M. (2006) Factors Predicting Retention in Treatment: 10-Year Experience of a Methadone Maintenance Treatment (MMT) Clinic in Israel. Drug Alcohol Dependence, 82, 211-217. http://dx.doi.org/10.1016/j.drugalcdep.2005.09.004

[12] Lequeille, X., Launay, C., Dervaux, A. and Kanit, M. (2009) Abuse of Alcohol and Benzodiazepine during Substitution Therapy in Heroin Addicts: A Review of the Literature. Encéphale, 35, 220-225.

[13] Garcia-Portilla, M.P.I., Bobes-Bascaran, M.T., Bascaran, M.T., Saiz, P.A. and Bobes, J. (2014) Long Term Outcomes of Pharmacological Treatments for Opioid Dependence: Does Methadone Still Lead the Pack? British Journal of Clinical Pharmacology, 77, 272-284. http://dx.doi.org/10.1111/bcp.12031

[14] Cobos, J.P., Trujols, J., Siñol, N. and Batlle, F. (2014) Development and Validation of the Scale to Assess Satisfaction with Medications for Addiction Treatment-Methadone for Heroin Addiction (SASMAT-METHER). Drug Alcohol Dependence, 142, 79-85.

http://dx.doi.org/10.1016/j.drugalcdep.2014.05.024

[15] De Maeyer, J., Vanderplasschen, W. and Broekeart, E. (2010) Quality of Life among OpiateDependent Individuals, a Review of the Literature. International Journal of Drug Policy, 21, 364-380. http://dx.doi.org/10.1016/j.drugpo.2010.01.010

[16] Ruefli, T. and Rogers, S.J. (2004) How Do the Drug Users Define Their Progress in Harm Reduction Programs? Qualitative Research to Develop Usersgenereted Outcomes. Harm Reduction Journal, 1, 8. http://dx.doi.org/10.1186/1477-7517-1-8

[17] Carr, D., Freedman, V.A., Cornman, J.C. and Schwarz, N. (2014) Happy Marriage, Happy Life? Marital Quality and Subjective Well-Being in Later Life. Journal of Marriage and Family, 76, 930-948. http://dx.doi.org/10.1111/jomf.12133

[18] Margelisch, K., Schneewind, K.A., Violette, J. and Perrig-Chiello, P. (2015) Marital Stability, Satisfaction and Well-Being in Old Age: Variability and Continuity in Long-Term Conti- 
nuously Married Older Persons. Aging Mental Health, 29, 1-10.

http://dx.doi.org/10.1080/13607863.2015.1102197

[19] Tavares, D., Arduini, G.O., Martins, N.P., Dias, F.A. and Ferreira, L.A. (2015) Socioeconomic Characteristics and Quality of Life of Urban and Rural Elderly People with Heart Disease. Revista Gaúcha de Enfermagem, 36, 21-27. http://dx.doi.org/10.1590/1983-1447.2015.03.45470

[20] Kurpas, D., Mroczek, B. and Bielska, D. (2014) Rural and Urban Disparities in Quality of Life and Health-Related Behaviors among Chronically Ill Patients. Rural and Remote Health, 14, 2485.

[21] Chan, G.C., Leung, J., Quinn, C., Kelly, A.B., Connor, J.P., Weier, M. and Hall, W.D. (2015) Rural and Urban Differences in Adolescent Alcohol Use, Alcohol Supply, and Parental Drinking. Journal of Rural Health, 32, 280-286. http://dx.doi.org/10.1111/jrh.12151

[22] Pawłowska, B., Zygo, M., Potembska, E., Kapka-Skrzypczak, L., Dreher, P. and Kędzierski, Z. (2014) Psychoactive Substances Use Experience and Addiction or Risk of Addiction among by Polish Adolescents Living in Rural and Urban Areas. Annals of Agricultural and Environmental Medicine, 21, 776-782. http://dx.doi.org/10.5604/12321966.1129932

[23] Draus, P., Roddy, J. and Greenwald, M. (2012) Heroin Mismatch in the Motor City: Addiction, Segregation, and the Geography of Opportunity. Journal of Ethnicity in Substance Abuse, 11, 149-173. http://dx.doi.org/10.1080/15332640.2012.675246

[24] Leukefeld, C.G., Narevic, E., Hiller, M.L., Staton, M., Logan, T.K., Gillespie, W., Webster, J.M., Garrity, T.F. and Purvis, R. (2002) Alcohol and Drug Use among Rural and Urban Incarcerated Substance Abusers. International Journal of Offender Therapy and Comparative Criminology, 46, 715-728. http://dx.doi.org/10.1177/0306624X02238164

[25] Millson, P.E., Challacombe, L., Villeneuve, P.J., Fischer, B., Strike, C.J., Myers, T., Shore, R., Hopkins, S., Raftis, S. and Pearson, M. (2004) Self-Perceived Health among Canadian Opiate Users: A Comparison to the General Population and to Other Chronic Disease Populations. Canadian Journal of Public Health, 95, 99-103.

[26] Chahua, M., Sánchez-Niubò, A., Torrens, M., Sordo, L., Bravo, M.J., Brugal, M.T. and Domingo-Salvany, A. (2015) Quality of Life in a Community Sample of Young Cocaine and/or Heroin Users: The Role of Mental Disorders. The ITINERE Project Group, Quality of Life Research, 24, 2129-2137. http://dx.doi.org/10.1007/s11136-015-0943-5

[27] Astals, M., Domingo-Salvany, A., Buenaventura, C.C., Tato, J., Vazquez, J.M., MartínSantos, R. and Torrens, M. (2008) Impact of Substance Dependence and Dual Diagnosis on the Quality of Life of Heroin Users Seeking Treatment. Substance Use \& Misuse, 43, 612632. http://dx.doi.org/10.1080/10826080701204813

[28] Goldberg, D.P. and Hillier V.F. (1979) A Scaled Version of the General Health Questionnaire. Psychological Medicine, 9, 139-145. http://dx.doi.org/10.1017/S0033291700021644

[29] Kihç, C., Rezaki, M., Rezaki, B., Kaplan, I., Özgen, G., Sagduyu, A. and Özturk, M.O. (1997) General Health Questionnaire (GHQ12 \& GHQ28): Psychometric Properties and Factor Structure of the Scales in a Turkish Primary Care Sample. Social Psychiatry and Psychiatric Epidemiology, 32, 327-331. http://dx.doi.org/10.1007/BF00805437

[30] Politi, P.L., Piccinelli, M. and Wilkinson, G.R. (1994) Eliability, Validity and Factor Structure of the 12-Item General Health Questionnaire among Young Males in Italy. Acta Psychiatrica Scandinavica, 90, 432-437. http://dx.doi.org/10.1111/j.1600-0447.1994.tb01620.x

[31] Piccinelli, M., Bisoffi, G., Bon, M.G., Cunico, L. and Tansella, M. (1993) Validity and Test-Retest Reliability of the Italian Version of the 12-Item General Health Questionnaire 
in General Practice: A Comparison between Three Scoring Methods. Comprehensive Psychiatry, 34, 198-205. http://dx.doi.org/10.1016/0010-440X(93)90048-9

[32] Karow, A., Verthein, U., Pukrop, R., Reimer, J., Haasen, C., Krausz, M. and Schäfer, I. (2011) Quality of Life Profiles and Changes in the Course of Maintenance Treatment among 1,015 Patients with Severe Opioid Dependence. Substance Use \& Misuse, 46, 705715. http://dx.doi.org/10.3109/10826084.2010.509854

[33] Quaglio, G.L., Lugoboni, F., Pajusco, B., Fornasiero, A., Lechi, A., Mezzelani, P., Pattaro, C., Des Jarlais, D.C. and GICS (2004) Heterosexual Relationships among Heroin Users in Italy. Drug and Alcohol Dependence, 75, 207-213. http://dx.doi.org/10.1016/j.drugalcdep.2004.03.002

[34] Quaglio, G.L., Lugoboni, F., Pattaro, C., Investigators, G., Montanari, L., Mezzelani, P., Lechi, A. and Des Jarlais, D.C. (2006) Patients in Long-Term Maintenance Therapy for Drug Use in Italy: Analysis of Some Parameters of Social Integration and Serological Status for Infectious Diseases in a Cohort of 1091 Patients. BMC Public Health, 6, 216-227. http://dx.doi.org/10.1186/1471-2458-6-216

[35] Domingo-Salvany, A., Brugal, M.T., Barrio, G., González-Saiz, F., Bravo, M.J. and De la Fuente, L. (2010) Gender Differences in Health Related Quality of Life of Young Heroin Users. Health and Quality of Life Outcomes, 8, 145. http://dx.doi.org/10.1186/1477-7525-8-145

[36] Bawor, M., Dennis, B.B., Anglin, R., Steiner, M., Thabane, L. and Samaan, Z. (2014) Sex Differences in Outcomes of Methadone Maintenance Treatment for Opioid Addiction: A Systematic Review Protocol. Systematic Reviews, 3, 45. http://dx.doi.org/10.1186/2046-4053-3-45

[37] Guydish, J., Passalacqua, E., Pagano, A., Martínez, A., Le, T., Chun, J.S., Tajima, B., Docto, L., Garina, D. and Delucchi, K. (2015) An International Systematic Review of Smoking Prevalence in Addiction Treatment. Addiction, 111, 220-230. http://dx.doi.org/10.1111/add.13099

[38] Rigliano, P. (2004) Doppia diagnosi, tra tossicodipendenza e psicopatologia. Raffaello Cortina Editore, Milano.

[39] Whelan, P.J. and Remski, K. (2012) Buprenorphine vs Methadone Treatment: A Review of Evidence in Both Developed and Developing Worlds. Journal of Neurosciences in Rural Practice, 3, 45-50. http://dx.doi.org/10.4103/0976-3147.91934

[40] Quaglio, G.L., Lugoboni, F., Pattaro, C., Investigators, G., Mezzelani, P., Lechi, A. and Des Jarlais, D.C. (2008) Erectile Dysfunction in Male Heroin Users, Receiving Methadone and Buprenorphine Maintenance Treatment. Drug and Alcohol Dependence, 94, 12-18. http://dx.doi.org/10.1016/j.drugalcdep.2007.09.025 
Submit or recommend next manuscript to SCIRP and we will provide best service for you:

Accepting pre-submission inquiries through Email, Facebook, LinkedIn, Twitter, etc. A wide selection of journals (inclusive of 9 subjects, more than 200 journals)

Providing 24-hour high-quality service

User-friendly online submission system

Fair and swift peer-review system

Efficient typesetting and proofreading procedure

Display of the result of downloads and visits, as well as the number of cited articles

Maximum dissemination of your research work

Submit your manuscript at: http://papersubmission.scirp.org/ 